\title{
Cher(e)s collègues, Cher(e)s ami(e)s,
}

Au cours de la réunion d'hiver de la Société française de médecine et de chirurgie du pied, qui s'est déroulée le 29 novembre 2003 , le conseil d'administration a été renouvelé.

Je remercie par la présente mes collègues qui m'ont élue à l'unanimité au poste de Président et j'espère être digne de leur confiance.

J'ai donc l'honneur et la charge de conduire la Société française de médecine et de chirurgie du pied pour trois ans.

Au cours de ce mandat, je souhaite valoriser notre société et développer la pluridisciplinarité. En effet, le pied est un " outil » merveilleux sur lequel nous prenons appui et grâce auquel, bien commandé, nous pouvons marcher. La déambulation est extrêmement précieuse et doit à tout prix être conservée, récupérée, améliorée. Les disciplines sont multiples à intervenir pour atteindre ce but. Dans cette communauté d'intérêt, il importe de travailler ensemble, toutes disciplines confondues, afin que chacun apporte sa spécificité et ses innovations, dans l'intérêt de nos patients.

Le pied est partie d'un tout, qui doit être considéré pour une évaluation harmonieuse de l'individu.

Enfin, les possibilités et les buts sont également différents selon les âges et les pathologies. Ces critères seront pris en compte dans l'approche globale.

Voici mes vœux les plus chers en ce début d'année. Que 2004 nous fournisse la capacité de mener à bien, dans un élan commun, notre projet dans un climat de chaleureuse amitié. 